\title{
Cultural Connotations, Developmental Dilemmas and Sustainable Development of Traditional Handicrafts: A Case Study of Xiangxi Bamboo- weaving
}

\author{
Shuangyan Guo ${ }^{1, *}$ Jianghui $\mathrm{Xu}^{1}$
}

${ }^{1}$ Research Center of Chinese Village Culture, Central South University, Changsha, Hunan, China
${ }^{*}$ Corresponding author. Email: syan5299@outlook.com

\begin{abstract}
This paper aims to contribute to studies on traditional handicrafts by taking Xiangxi bamboo-weaving as a case study. The history of Xiangxi bamboo-weaving is time-honored and its cultural connotations could be demonstrated as animism and ethnic unity. However, with the pace of urbanization and demographic changes, Xiangxi bamboo-weaving is faced with various kinds of developmental dilemmas, which mainly include the extrusion of modernization, the ageing trend of artisans and the hinderances in realizing industrialized development. In order to realize sustainable development, this paper puts forward four possible approaches, that is to expand the market of bamboo-weaving products through proper market positioning, structure-readjusting and propaganda, to broaden the inheritance talent pool through organizing professional associations and holding regular exchange and discussion seminars, to promote bamboo-weaving production cooperatives, and to establish a living museum of Xiangxi bamboo-weaving culture. As a representative of traditional handicrafts in Hunan, the study of Xiangxi bamboo-weaving has important reference significance for the development of bamboo-weaving crafts in Fujian, Guangdong, Sichuan, Zhejiang and so forth. The study on traditional handicrafts deserves the joint attention and effort of contemporary academic researchers.
\end{abstract}

Keywords: Traditional handicrafts, Xiangxi bamboo-weaving, Culture connotations, Developmental dilemmas, Sustainable development.

\section{INTRODUCTION}

Bamboo has a long history in China. The cultural value of bamboo lies in building construction, food and cooking, folk feast and religion activity, and arts [1]. Since ancient times, Chinese ancestors have been using bambooweaving products as tools for production and life. Bamboo-weaving gains popularity in Guangdong, Fujian, Hunan, Sichuan, Anhui and Zhejiang provinces, and has become an indispensable part of traditional cultures in the related areas. Traditional bamboo-weaving in Hunan province could be traced back to the Gaomiao Culture Period more than 7,000 years ago, when a female skeleton on a bamboo mat was unearthed in 2004 [2]. Among Hunan traditional bamboo-weaving crafts stands out the Xiangxi bamboo-weaving. Xiang is short for Hunan province, xi means west. Xiangxi is simplified for Xiangxi Tujia and Miao Autonomous Prefecture, which lies in the west of Hunan province. Xiangxi bamboo-weaving is a traditional handicraft of the Miao people, which is mainly inherited by succession or apprenticeship. "Xiangxi is the world of the back-baskets, and a world by the back-baskets" is a widely spread proverb in Wuling Mountain areas. The advantageous natural environment and social history of Xiangxi has laid the foundation for Miao people's bamboo-weaving skill with unique shapes, delicate patterns and artistic conception. In 2008, Xiangxi bambooweaving technique was included in the second batch of Hunan's provincial intangible cultural heritage list.

However, with the pace of urbanization and demographic changes, Xiangxi bamboo-weaving is 
faced with varied kinds of developmental dilemmas. This paper intends to discuss cultural connotations and developmental dilemmas of Xiangxi bambooweaving, and to explore possible approaches to its sustainable development in modern era, so as to provide reference for the sustainability of traditional handicrafts.

\section{CULTURAL CONNOTATIONS THROUGH HISTORY}

The history of Xiangxi bamboo-weaving is time-honored. Pieces of bamboo mats unearthed from the Gaomiao Culture Period testify that the history of bamboo-weaving in Xiangxi could be traced back to the Neolithic Age about 7400 years ago. In the archaeological excavation of the cliff tombs along Youshui River, bamboo mats from Tang and Song Dynasties were also unearthed [3]. These discoveries are not only precious historical remains of Xiangxi bamboo-weaving, but also the proof of the origin, development and spread of bamboo-weaving craftsmanship in Xiangxi for thousands of years.

Located in Western Hunan, Xiangxi is close to Wuling Mountain areas with large bamboo forests and diverse types of bamboos. Due to its mountainous landform, Xiangxi was inconvenient in traffic and underdeveloped in trade in history, the Miao people living in Xiangxi had to adapt to local conditions by using homegrown bamboos as raw materials, cutting bamboos into bamboo strips, and weaving various utensils for production and everyday life, which provided social and historical conditions for the emergence and continuous development of bamboo-weaving crafts. There are many types of bamboo-weaving products in Xiangxi, be they three-dimensional or planar. Three-dimensional bamboo-weaving products mainly include: bamboo back-baskets, hats, cages, baskets, sieves, tables, chairs, flower baskets, bird cages and so forth. The plane bamboo-weaving products contain bamboo mats, bamboo-weaving paintings, etc. There are abundant fabrication techniques and ornamentation styles in bambooweaving products, and the same kind of bambooweaving product often presents various styles with differentiated models. For example, bamboo backbaskets could be further divided into laundry backbaskets, children back-baskets, farming backbaskets, water back-baskets, decorative backbaskets, etc., covering almost every aspect of local residents' production and life. For bamboo weavers, weaving bamboo products has become an important way to make a living for generations, as the craftsmanship is passed down by apprentice or inheritance.

In addition to the practical value of bambooweaving products, Xiangxi bamboo-weaving also has important cultural connotations, which are of great significance in studying the history and culture of traditional handicrafts, ethnic cultures and regional exchanges in Xiangxi. On one hand, Xiangxi bamboo-weaving embodies the simple thought of creation and innovation based on specific social conditions, of which human beings and the nature coexist in harmony and things unite with humanity. It would be safe to say that bamboo-weaving reflects Xiangxi people's animistic view of nature, aesthetic taste of being close to nature, and life philosophy of being happy and contented. Therefore, Xiangxi bambooweaving is not only one outstanding representative of traditional handicrafts, but also an important component of local traditional cultures. On the other hand, Xiangxi bamboo-weaving promotes regional unity among ethnic groups. All through history, Xiangxi bamboo-weaving craftsmanship and products have become the collective memories of ethnic groups in Xiangxi. Take the most commonly used back-baskets for instance. Historically, with geographically mountainous landscape came narrow roads, which made vehicles difficult or impossible to pass, and the flow of goods mainly relied on manpower. Back-baskets freed people off their hands, thus facilitated climbing along mountainous journeys with supplies or goods. Besides, as the conflicts and disputes between Miao ethnic groups and the Han regime persisted, wars occurred from time to time. Memories of ethnic interaction and ethnic migration caused by war were also woven in bamboo-weaving products represented by backbaskets.

Upon entering the Millennia, there has been a worldwide upsurge in the protection of intangible cultural heritages. With the active participation of officials, experts and scholars, the Chinese government has set up a four-level system of intangible cultural heritages' protection [4]. In 2008, Xiangxi bamboo-weaving was included in the intangible cultural heritage list of Hunan province, making this regional handcraft well-known to the general public in Hunan and even in China. From traditional handicraft to intangible cultural heritage, the change of appellation or title heralds the change of ideas through times. In traditional society, Xiangxi bamboo-weaving was regarded more as a 
craft that could compile practical products and a way to make a living. Nowadays, under the appeal of scholars and the governments, people are increasingly aware of the historical value and cultural significance of bamboo-weaving as a traditional handicraft. Bamboo-weaving is more an indispensable part of Xiangxi traditional cultures than a mere craft.

\section{DEVELOPMENTAL DILEMMAS IN NEW ERA}

It is gratifying that Xiangxi bamboo-weaving has been included in Hunan provincial intangible cultural heritages and has attracted attention from all sides. However, with the development of Chinese society, especially with the modernization process of rural areas, great changes have been taken place in rural China. Xiangxi bambooweaving, as well as other traditional handicrafts, is faced with varied kinds of developmental dilemmas due to the impact of urbanization and demographic changes, which could be further elucidated as follows.

First of all, Xiangxi bamboo-weaving is toughly extruded by modernization. Modernization is often entwined with globalization, industrialization and urbanization, which has brought quantitative household appliances and living products at lower prices to rural areas. China's modernization started late, but developed rapidly. Since the reform and opening up, China's market economy has further stimulated the vitality of the national economy. After China's accession to the WTO, China has tried its best to integrate into the world market and economic structure. A significant increase in substitutes and supplements has been witnessed in the past decades, the dependence of rural residents on bamboo-weaving products has decreased, rendering the demand for bamboo-weaving products gradually weakened. The rapid pace of modernization makes it difficult for traditional manual work to adapt to the development of industrialization [5], and the replacement of plastic products dispels emotional connections between human beings and things [6].

Secondly, the ageing trend of Xiangxi bambooweaving craftsmen is severe. Under the leadership of governments at all levels, a group of people inheriting this intangible cultural heritage has been identified since 2008. The existing inheritors of Xiangxi bamboo-weaving are advanced in age on the whole, while many of them are highly skilled and experienced. What's more, the number of newly identified inheritors is insufficient, and the overall number of inheritors is decreasing [7]. The younger adults' reluctance to learn or engage in bamboo-weaving is the major cause. In Xiangxi bamboo-weaving industry, the products cost manpower, but the value of products is low with limited profit. Young people are not optimistic about the prospect of bamboo-weaving industry concerning the shrinking consumer market. Besides, they have more employment opportunities than their predecessors. For them, many jobs pay better than being a bamboo-weaving craftsman. They are disengaged from agricultural production and show little interest in traditional handicrafts. The shortage of talents is the main problem that the development of Xiangxi bamboo-weaving confronts.

Finally, the industrialized development of Xiangxi bamboo-weaving is hindered by multiple predicaments. As a traditional craft, Xiangxi bamboo-weaving used to be inherited by succession or apprenticeship. Through teaching and practice, the craftsmen of Xiangxi bamboo-weaving impart experience and skills to their disciples or offspring. After grasping most of the master's skills, the apprentice becomes another bamboo-weaving craftsman, through which this ancient handicraft is able to survive for thousands of years without interruption. Besides, the production and sale of bamboo-weaving products are mainly based on families. Several generations in rural families are engaged in bamboo-weaving, while only one person in the families is capable of weaving bamboo, showing the characteristics of scattered distribution, limited producers, unstable output and sales volume. The features of being scattered around and relatively independent make it difficult for Xiangxi bamboo-weaving to realize industrialized and large-scale development. Smallscale family workshops are not conducive to resisting the impact of industrialized products and the shrinking market. Concerning the instability of output and sales, some craftsmen have to look for other ways to make ends meet, which makes the situation even worse and restricts the long-term development of Xiangxi bamboo-weaving.

\section{POSSIBLE APPROACHES TO THE SUSTAINABLE DEVELOPMENT}

With the pace of urbanization and demographic changes, Xiangxi bamboo-weaving is confronted with three developmental dilemmas, namely the extrusion of modernization, the ageing trend of artisans and the hinderances in realizing 
industrialized development. After the emergence of these dismaying situations, the Chinese academic researchers set out to study the marginalized traditional handcraft. Guiding Xiangxi bambooweaving craft to adapt to the modern society and promoting its industrialized development are urgently needed, and possible approaches to realize the sustainable development of Xiangxi bambooweaving are as follows.

\subsection{Expanding Markets Through Multiple Channels}

Intangible cultural heritage products, which were once traded and circulated in the market in history, are still suitable for modern development through proper market operation [8]. The decreasing market demand exerted by modernization is the pressure that the development of Xiangxi bamboo-weaving confronts, and measures must be taken to broaden the market and promote the long-term development of bambooweaving products. First, to expand the market, the market positioning should not be limited to the local, but be aimed at the markets of home and abroad. Though Xiangxi bamboo-weaving craft rooted in western Hunan, the products may meet the needs of people in much broader areas with the help of China's fast-growing internet e-commerce platforms. Secondly, market fitness is another key factor [9]. In addition to expanding the sales area, Xiangxi bamboo-weaving could also readjust its structure and enrich its products according to the needs of modern life with proper designs [10][11][12], such as bamboo mats, food steamers, fruit baskets, coasters as well as other decorative bamboo-weaving products. Last but not least, propaganda is of high significance. In the internet era, self-media and short video platforms can be used as propaganda tools and platforms to gain the popularity of Xiangxi bamboo-weaving products.

\subsection{Broadening the Inheritance Talent Pool}

Nowadays, most of the remaining inheritors of Xiangxi bamboo-weaving craft are relatively old. Increasing the number of younger craftsmen could effectively alleviate the aging trend of Xiangxi bamboo-weaving artisans, who are characterized by a decrease in the number and an advance in age. For the sustainability of intangible cultural heritages, especially traditional handicrafts, inheritors are important and indispensable carriers and imparters, which necessitates the cultivation of
Xiangxi bamboo-weaving craftsmen. There are two key points. One is to increase the number of craftsmen, and the other is to ensure their skills and quality. On one hand, the association of Xiangxi bamboo-weaving industry could be organized, so as to attract bamboo-weaving practitioners, who are interested in or aspiring to traditional handicrafts. During the process of personnel training organized by the professional social organizations, the candidates of inheritance talents could be spotted, thus expanding the inheritance talent pool. On the other hand, technical exchanges and discussions should be held regularly, so that bamboo-weaving craftsmen could maintain a high level of skills and expertise through rival competing and reference learning, which would also become a good means of advertising and promotion via live broadcast and media coverage.

\subsection{Promoting Bamboo-weaving Production Cooperatives}

In Xiangxi areas, the manufacturing and selling of bamboo-weaving products are mainly based on scattered family workshops, which is not easy to counteract the consequences of modernization or conducive to long-term development of Xiangxi bamboo-weaving. In recent years, the development mode of bamboo-weaving production cooperatives has been tried in Xiangxi, and has achieved great success, of which the Benshun Bamboo Art Cooperative in Bier Town, Baojing County, is worth mentioning. It has absorbed dozens of local bamboo-weaving craftsmen with more than 40 employees, and has applied for a number of patents. The cooperative undertakes orders for bambooweaving products at home and abroad, with an annual sale of nearly one million [13]. In the process of operation, Benshun Bamboo Art Cooperative not only gains its own popularity, but also spreads Xiangxi bamboo-weaving culture to the world with its products. Gathering bambooweaving craftsmen together to form a cooperative not only improves the production capacity, but also has an access to hiring special publicity and sales personnel to make the division of labor more detailed, thus transforming the scattered family workshop-style operation into small-scale cooperative operation and laying a good foundation for the industrialized development of Xiangxi bamboo-weaving. Moreover, compared with family workshops, cooperatives are more capable of achieving cooperation with large units, such as supermarkets, furniture malls and handicraft 
manufacturers, so as to obtain steady and continuous orders.

\subsection{Establishing a Living Museum in Western Hunan}

In December 2019, the Ministry of Culture and Tourism of China officially announced the Tujia and Miao Cultural and Ecological Protection Experimental Zone in Wuling Mountain Area (Xiangxi) as a national cultural and ecological protection zone [14]. The idea of establishing a living Xiangxi bamboo-weaving cultural museum is innovative and conducive to promoting the integration of Xiangxi bamboo-weaving development into the construction process of the Tujia and Miao Cultural Ecological Protection Zone in Wuling Mountain Area (Xiangxi), and plays an active role in the protection and inheritance of traditional handicrafts in Xiangxi. As an intangible cultural heritage project, Xiangxi bamboo-weaving is inseparable from the natural environment and regional cultures in Xiangxi. When it comes to the protection, inheritance and development of Xiangxi bamboo-weaving crafts, the tools, work places and bamboo-weaving products must be taken into consideration. The living museum of Xiangxi bamboo-weaving doesn't necessarily be located within certain buildings, but should try its best to present the natural and humanistic environment, and cultural connotations of Xiangxi bamboo-weaving. What's more, it could cooperate with craftsmen or bamboo-weaving production cooperatives by showing the process of weaving bamboo products by craftsmen on the spot. Establishing a living museum of Xiangxi bambooweaving culture is an feasible approach to realize effective protection and sustainable development of Xiangxi bamboo-weaving.

\section{CONCLUSION}

Xiangxi bamboo-weaving, a traditional handicraft in western Hunan, was included in Hunan's provincial intangible cultural heritage list in 2008, which reflexed the recognition of Xiangxi bamboo-weaving's value and significance by the government and academia. Since then, Xiangxi bamboo-weaving has received more attention and popularity from Chinese academic circles. However, with the pace of modernization and demographic changes, Xiangxi bamboo-weaving is faced with diverse developmental dilemmas, which mainly contain the extrusion of modernization, the ageing trend of artisans and the hinderances in realizing industrialized development. In this paper, the authors put forward four possible development approaches from four different angles of market, talents, development mode, and cultural display to expand the market of bamboo-weaving products through proper market positioning, structurereadjusting and propaganda, to broaden the inheritance talent pool through organizing professional associations and holding regular exchange and discussion seminars, to promote bamboo-weaving production cooperatives, and to establish a living museum of Xiangxi bambooweaving culture.

In traditional society, Xiangxi bamboo-weaving products were made for sale and bamboo-weaving craftsmen earned income by selling bambooweaving products. Nowadays, Xiangxi bambooweaving becomes marginalized and its practical value has yielded to its cultural one. In the tide of industrialization, globalization and urbanization, Xiangxi bamboo-weaving must brave the weather by readjusting itself according to the modern market demand, applying reasonable management methods and actively integrating into the market economy of the new era, which is an important and unchanging law for market-oriented traditional handicrafts to achieve sustainable development. Although bamboo-weaving crafts in different places may differ in production process, shape, style or pattern, their commonly shared cultures and developmental dilemmas are beyond doubt. As a representative of traditional handicrafts in Hunan, the study of Xiangxi bamboo-weaving has important reference significance for the development of bamboo-weaving crafts in Fujian, Guangdong, Sichuan, Zhejiang and so forth. On the road to the great rejuvenation of the Chinese nation, the study on traditional handicrafts is worthy of the joint attention and effort of contemporary academic researchers.

\section{AUTHORS' CONTRIBUTIONS}

Shuangyan Guo wrote the manuscript and Jianghui $\mathrm{Xu}$ contributed to revising and editing.

\section{REFERENCES}

[1] Yang, Q.; Duan, Z.-B.; Wang, Z.-L.; He, K.H.; Sun, Q.-X. and Peng, Z.-H. (2008), Bamboo resources, utilization and exsitu conservation in Xishuangbanna, South-eastern China. Journal of Forestry Research, No. 19, pp. $79-83$. 
[2] He, G. and Chen, L.-W. (2007), Gaomiao culture and its external communication and influence. Cultural Relics in Southern China, No. 02, pp. 51-60+90.

[3] Hunan Provincial Department of Culture. (2009), Hunan Intangible Cultural Heritage List, Hunan People's Publishing House.

[4] The State Council.(2006). Circular of the State Council on Strengthening the Protection of Cultural Heritage. Bulletin of the State Council of the People's Republic of China, No. 5, pp. 31-34.

[5] Tang, T. and Shi, J. (2020), The home furnishing design based on the bamboo weaving craft in western of Hunan. Design, No. 33, pp. 102-104.

[6] Li, B.-S. (2016), Xiangxi Miao Bamboo Culture and Modern Transformation. Guizhou Ethnic Studies, No. 37, pp. 81-84.

[7] Wang, X.; Zhang, S.; Zhang, S. and Chen, Y. (2020), Research on the Regeneration of Endangered Traditional Handicraft Art in Modern Life: Taking the Bamboo Knitting Art of Dongyang as an Example. Advances in Intelligent Systems and Computing, pp. 581588.

[8] Yuan, L. (2010), Several Issues on Scientific Protection of Intangible Cultural Heritage. Jiangxi Social Sciences, No. 09, pp. 20-25.

[9] Gao, Q. (2016), Think on the culture an contemporary transformation of Back-baskets in Xiangxi. Chinese national Expo, No. 11, pp. 3-4.

[10] Zhang, Y.-J. (2014) A study of Bamboo weaving culture and craftsmanship in Wuling Mountain Region. Journal of Huaihua University, No. 33, pp. 31-33.

[11] Liu, Z.-M. and Jiang, Y.-Y. (2018), Construction and design of Xiangxi bamboo weaving technology cultural gene pedigree. Journal of Bamboo Research, No. 37, pp. 5663.

[12] Zhang, Y-H. and Liu, W.-J. (2020), Research on the redesign of bamboo weaving in western Hunan province based on modern life behaviors. China Forest Products Industry, No. 57, pp. 47-50.
[13] Zuo,Y.-Y. and Li, Q.(2018) Research on the Strategy of Creating Xiangxi Bambooweaving Brand under the Precise Poverty Alleviation Strategy — Taking "Benshun Bamboo Art Cooperative" in Bier Village, Baojing County, Xiangxi as an Example. Art Paronama, No. 02, pp. 76-77.

[14] Ministry of Culture and Tourism of the People's Republic of China. (2019), Notice on the Announcement of the List of National Cultural Ecological Protected Areas [EB/OL] http://zwgk.mct.gov.cn/zfxxgkml/fwzwhyc/20 2012/t20201206_916890.html. 